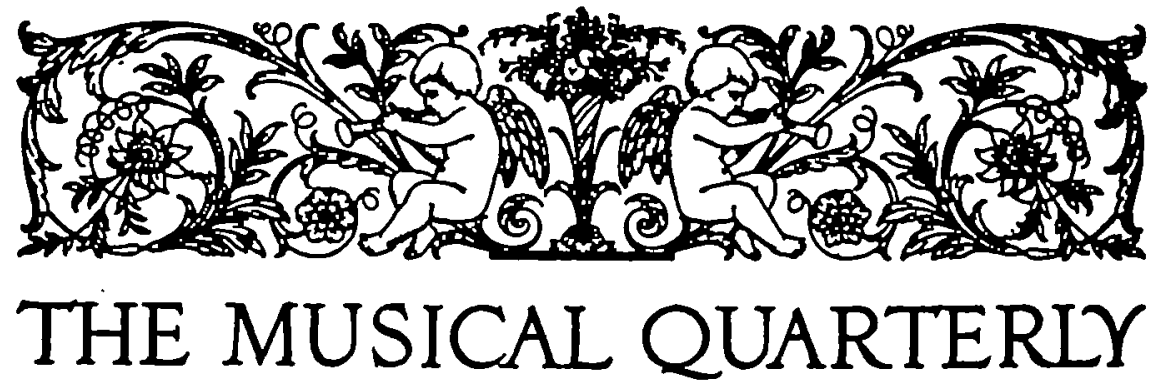

VOL III

JULY, 1917

NO. 3

\title{
THE CREATORS OF MODERN MUSICAL IDEALITIES
}

\section{By GUIDO ALBERTO FANO ${ }^{1}$}

$I^{\mathrm{I}}$

DEALITY is art: its aim to infuse into music new spirit and understanding and impose a taste for them on the public, a malevolent tyrant toward most composers, especially the dramatic type. The grandeur of this conception debars really great masters from regarding music as a diversion for the idle or those wearied by the day's labor. Thus Beethoven is wholly penetrated with the heroic spirit of the Revolution; Berlioz pours out the richness and variety of his temperament in musical creations, and also in vast literary works; Franz Liszt, pianist, orchestral director, composer, and author of valuable writings, full of imagination and charged with his intense personality, hails with enthusiasm tive July revolution of 1830 , receives from Saint Simonism a notable impulse in the development of his individuality and finally, fascinated by Catholic thought, and moved by a natural inclination toward mysticism, in 1865 takes minor orders and becomes an abbe; Richard. Wagner composes the dramatic poems for his music and sets forth in fully developed theories his thoughts on art and philosophy, his dreams of social and political revenges, and the sad realities of life's experience; Franck, an organist and fervent Catholic, reading the "Critique of Pure Reason," smiles and exclaims: "C'est très amusant!"

... The bond that most closely unites these great men as artists is their conception of music as an admirable medium of

\footnotetext{
1 From the flasl chapter in the book "Nelle vita del ritmo" (Neples, 1816) with permiarion of the author, potent in Italy's musical life as pianist, conductor, compaser and director of the Royal Conservatory in Naples.-Ed. 
expression, independent of rigid traditional forms and of the schematism of the strictly classical school.

Music,-it is Berlioz who speaks, -is the art of affecting, by combinations of sounds, men of intelligence endowed with special and trained organs. . . . Music associating itself with ideas, which it has a thousand ways of awakening, increases the intensity of its action by the power of what we call poetry. ... directing at one and the same time all its energies upon the ear, which it both charms and skilfully offends, upon the nervous system, which it excites to a high degree, upon the circulation of the blood, which it accelerates, upon the brain, which it inflames, upon the heart, which it causes to dilate and redouble its beats, upon thought, which it expands immeasurably and launches into the regions of the infinite. It acts in its own peculiar sphere, that is, upon persons in whom the musical sense really exists.

In this definition of music made by Berlioz in 1837 and reprinted twenty-five years later, definition which may be considered his musical credo,- -lies in my opinion the whole program of the art of sound as developing from the time of Beethoven's maturity until to-day, in opposition to music of pure form, while in the Hanslickian conception of it as merely the play of beautiful forms comparable to that of a kaleidoscope, rests the principle affirmed by every adherent of "pure music." Not new but certainly never more vigorous than from the period marked by the genius of Beethoven to our own time, this controversy requires further explanation in order that we may more effectively outline the aforementioned figures, who are of the greatest importance,more especially Berlioz and Franck, -in the formation and development of the French school. Above all do not accept the oft-repeated statement that Classicism and Romanticism have little meaning in connection with musical art, that is, if these words be given their real significance, not the one just now dear to a goodly part of the Italian public, defining classical music as that which bores unspeakably and is conducive to slumber,notably the dramatic music of Richard Wagner! The ideas relating to Classicism and Romanticism will become clearer if one frees the principal elements from their exaggerations. It is true that Classicism in its decadence leads to art that is academic, and Romanticism to anarchy of forms and vacuous nebulosity of content, unless indeed it rises into the most sublimated mysticism. Now precisely the first characteristic of a classical musician, in the true sense of the word, is the reverence for rhythm taken in its wide significance of number and proportion in the larger parts as well as in details, a reverence which with lesser men 
may become arid, conventional, obvious, -80 to speak, $-8 y m-$ metry. Thus, - note the irony in the reversal of meaning of the word,-eminently classical in a certain sense were all the writers of the happier period of Italian opera,-Rossini, Bellini, Donizetti, Verdi,-because, and herein lies the origin of the opposition they aroused, especially in Wagner, they aimed to construct a piece of music rather than to let its form and content spring from the form and content of the poetry, which in fact was always written with reference to the music designed to accompany it. It is true in Italian opera that, whereas special regard was paid to rhythm in the construction of the part, there was apparently less in the construction of the scene, of the act, of the entire score, whence resulted a joining of part to part rather than an organic whole. The musician who is a thorough purist, for instance of the type of Brahms, has in view beyond the part, the entire structure, and furthermore,-in Italian opera this was lacking,gives particular heed to the harmonic and contrapuntal play of the separate voices, in which precisely consists beautiful form, the revolving kaleidoscope. Hence it may be said that classical music is first of all music in se and per se, with special regard to all therein that is architectural, and the form therefore springs from something anterior, to the conception of the musician who tarries, as it were, at the source, seeking there to retain and mold and dominate his creative force. It is clear that if this force be not vigorous and fervid the composer becomes academic, or worse still, scholastic-faults these last that, in spite of the oft-repeated assertion that Italians have imagination more vivid and pulsating - with sentiment than other nations, were and are very frequent precisely in Latin countries.

In a different fashion proceeds the romantic musician, although he does not compose with the design of being so classified. Excluding always the mere vulgar pleasure of the crowd, romanticism fixes as basis of the work of art not a preestablished model to be copied, not a formal archetype with which to constrain inspiration, but the spontaneous creation of the ego that feels, suffers, enjoys, aspires in the fullness of its freedom and craves the ineffable happiness of breaking the chains that bind it to earth. Consequently a work of art is the greater the more it reveals the stamp of a strong individuality, the more personal its content and unusual its form in adequate expression of that content; the more the rhythm in its elasticity, complex and detailed, inspires dream fancies and spiritual joys. Hence all that is romantic is not false, as Carducci said in a moment of ill-humor, 
but true, live and ardent; since individuals and not abstractions are real, and therefore the manifestations that express personality are more sincere than those created in an established mould. Even though romanticism may degenerate into vacuity and formlessness, that does not affect our conviction that the domain of living expression, free from formal preconceived rules, is the true field of the fertile art of infinitely conserving and reviving, just as the variety of individuals is infinite; and when it attains to the mysticism of a Parsifal, that art speaks to the soul the most profound language of the human race. Let this be said with all due respect to scientists and philosophers who hold in abhorrence the word mysticism.

.. . Let us now rapidly consider what are the characteristics that diversify and individualize, as men, as artists and as creatures of destiny, so to speak, the five great masters whom I regard as the creators of modern musical idealities pulsing with vitality.

The life of Ludwig van Beethoven displays in itself something of the heroic, the sublime, Promethean. Upon his pure and lofty brow is, as though engraved, a thought, which he expressed in a letter to Kanka during the Congress of Vienna outlining a touching synthesis of the faith, the ideality, the essence of one of the most powerful and saintly minds recorded in history. "Mir ist das geistige Reich das Liebste, und die Oberste aller geistlichen und weltlichen Monarchien." (To me the realm of the spirit is the dearest and the highest of all spiritual and worldly monarchies). The dominion of the mind over all the empires of this world; the religion of the spirit gradually victorious over other faiths, the republic of Plato a dream to be realized in human society; the persistent effort to overcome in oneself the bondage of matter, the malevolence of fate, and the tyranny of man; in musical art to hold essential depth of sentiment, liberty of form, humanity of content; a poetical, chaste aura, a refined and tender love of nature; such the life and soul of Ludwig van Beethoven. What signify the daily events of his existence dear to the myopic who delight in viewing and measuring great minds by their own narrow vision? Nothing if not precisely that adversities of fortune, domestic trials, financial difficulties, even the fate of deafness, so ineffably cruel for a musical genius, were unavailing to destroy a mind and soul such as those of Beethoven. Indeed Providence seemed to rejoice in multiplying in his pathway vexations and obstacles in order that, striking against the indestructible rock of his spirit, they might be transmuted into harmonies of unheard-of potency. There is profound 
truth in these words of Rolland: "What victory compares with this, what battle of Bonaparte, what sun of Austerlitz attain the glory of this superhuman effort, of this conquest, the greatest ever made by the Mind: an unfortunate, poor, infirm, solitary, sorrow become man, to whom the world denies joy, himself creates Joy to give to the world. He forges it out of his misery, as he expressed it in a proud phrase that sums up his life and is the motto of all heroic souls:

Durch Leiden Froude. (Joy through Sorrow.)"

Ludwig van Beethoven is the genius of the sonata form. But he is much more. All the most elevated records of modern musical idealities, as I propose to show, find in him the source from which rise and flow the multiform currents of contemporary musical life. As usual I refuse to be affected by the foolish talk of our puny young esthetes who consider Beethoven (and certain others) old fogies because they did not write their compositions in the Greek ecclesiastical tonality,-or something equally absurd,-but conceived them in the spirit, as it were, of the Monteverdian methods. Nor, on the other hand, am I moved by the opinion still held in our professional and official circles, that Beethoven should be considered and interpreted as belonging to the school that reveres the principle of authority and conservatism. As regards this point there can be no possible doubt, no agreement. Beethoven was a true and great creator because,-and when,he was able to transfuse into the sonata form, sterile in the hands of his predecessors, vigorous vital blood and so render it a free, varied, supremely efficacious manifestation of his multiform spiritual activities; he failed on the rare occasions when for practical reasons or in an attempt at adaptation, he denied his original independence. Therefore the truest and greatest disciples of Beethoven must be sought among those who defend with vigor the rights of the future, not those who, while calling themselves humble admirers of his genius, can only appreciate its form, not its vibrant subject-matter. In short liszt and Wagner on one hand, Berlioz and Franck on the other; somewhat less than they (and not invariably) Mendelssohn and Brahms.

Liszt himself thus luminously estimates the work of Ludwig van Beethoven:

For us musicians, the work of Beethoven is like the column of cloud and of fire that led the Israelites across the desert, $-a$ column of cloud to lead us by day, a column of fire to light us by night, so that 200 may march day and night. His obscurity and his light equally trace the 
way that we should follow; the one and the other are a perpetual commandment, an infallible revelation. If it fell to me to categorize the terms of the great master's thought as expressed in his sonatas, symphonies, and quartets, I should in truth scarcely be content with the division into three styles now quite generally adopted, which you have followed. [We quote a letter dated Dec. 2,1852 , sent from Weimar to William de Lene, the author of Beothooen and his Three Styles-_-but taking into consideration the points thus far raised, I would frankly put the great question which is the basis of musical criticism and esthetics at the point where Beethoven has brought us, that is, how far should traditional and conventional form necessarily determine the organism of thought?

The solution of this question, as revealed in Beethoven's own work, would lead me to divide the work not into three styles or periods, the words style and period can here be only corollary, subordinate terms of vague and ambiguous meaning-but quite logically into two categories: the first, that in which the traditional and accepted form contains and governs the thought of the master; the second, that in which the thought expands, destroys, re-creates, and fashions in response to.its needs and inspirations, the form and the style. Undoubtedly proceding in this way we arrive in a straight line at the persistent problems of authority and liberty. But why should we fear them? Fortunately in the realm of the fine arts they bring in their train none of the dangers and disasters that their fluctuations occasion in the practical and social world, because in the domain of the Beautiful genius alone is the authority, and dualism disappears; the notions of authority and liberty are restored to their primitive identity.

Excellent! But precisely because genius and genius alone, whether or not it be recognized of men, is supreme in freedom of creation, and, conversely, intuition alone is the promoter of genius, one must be even more positive than Liszt and his commentator, Jean Chantavoine, and declare unhesitatingly that where Beethoven himself was dominated by traditional form he expressed little or nothing that was worthy of him, and that composers succeding him who in his work set the principle of authority above that of liberty, understood him ill and became his imitators rather than his disciples. However, Chantavoine is right when he affirms,

Music, enfranchised by Beethoven, is now able to sing freely of the joys and sorrows of the world; it has been changed from science to conscience, and those shall be eternally his disciples who, without copying or imitating him, employ the liberty that he gained for them through suffering.

Beethoven bore wonderful fruits in the field of the sonatanotably for the pianoforte, of the quartet, and of symphonic music. But to understand him profoundly one should also study 
him as composer of songs, of dramatic and religious music, and as the thinker that he is revealed in his own letters and writings and in those of others. The effort to give an exalted poetic significance to musical art,-effort that is one of the most distinctive features of the modern tendency,-finally acquires in the mature Beethoven a clear and definite consciousness. And from the appearance of the first sonata for the pianoforte in $F$ minor, passion, clarity, dramatic force are the qualities that differentiate him, for instance, from Mozart and Haydn. Moreover, his ideality of content and lyrical emotion become continuously freer and more intense as the gradually transhumanized Beethoven finds in art and in art alone the reason and also the consolation of a life weighed down with suffering. Evidently the transitions cannot be defined in the category of his styles; they were now more marked, now less, according to seasons, circumstances, and his spiritual activity.

The difficulty of understanding and interpreting Beethoven's music, - whether as performer or conductor, -is unquestionably great as regards both the technique and the expression, but there is nothing more grossly erroneous, as I have shown, than an interpretation prevailingly rhythmical and formal, not permeated with intimate vibrant comprehension and sentiment, and a poetic penetration of the musical text. Yet even here what prejudices obscure the vision of interpreters, critics and professors, especially in Italy!

The sonorous combination in which the genius of Beethoven makes a truly aquiline flight is the quartet, now surely a field forever closed to any other fertilization. To the pianoforte, to symphonic forms and scenic music, even to those harmonies that find inspiration in the higher regions of human faith, new horizons of beauty and splendor were opened by this universal genius, who had no need of the many lines of training 80 complacently striven for by certain of our smaller intelligences.

... The moral figure of Frane Liszt is one of the purest and noblest known in the history of music. Reflect: a mind open to all the prizes, all the aspirations of life and modern thought, a man beloved and idolized as an incomparable virtuoso of the keyboard by multitudes of concert-goers and by the most clever and fascinating women of the various European aristocracies, an artist whose renown as a composer was marred and too little appreciated by very reason of the unanimous approval he received as concert player; a master of the pianoforte eagerly courted, followed, sought after, by students of every nationality; a 
musician truly continuing the tradition of the highest endeavours to give poetic and human significance to the art of sounds, and therefore the creator of new forms for the pianoforte, orchestra and voice,-yet even now only partially understood. What more required to fill an artist with pride in his achievements, or, on the other hand, with a certain bitterness because of the unjust contemporary estimate of his work as a composer? What more, I ask, to render him in any case solicitous only for his own glory and eager for new delights, new loves, for always greater and more perfect triumphs? But in the case of Liszt the contrary was true. Early attracted by the mysterious aroma of the Catholic contemplative life through very weariness of his agitated exuberant existence as youthful virtuoso, his mind fluctuated between a passionate enjoyment of amatory adventures and an inward aspiration toward ascetic calm. In Liszt this inner strife was very human and sincere, as evidenced in his art, pervaded with a sensuousness incomparably refined, - one might almost say immaterial,- and by poetic, religious and contemplative harmonies. In music one does not deceive those endowed with esthetic and psychological penetration. Hence it is futile and unfitting to seek for the practical reasons that may have determined the master to become an abbe, and don the cassock soon after the death of Prince von Wittgenstein, a death that finally rendered possible the marriage ceremony with the Princess.

While still unknown himself as a composer, he helped and protected others; always prompt and happy to discover vigorous young talents, he encouraged, stimulated, and spurred them on, not only with words, as is customary among musicians, but by performing and making known their works, placing at their disposal his very valuable authority with the public, the press and the powers that be,-even by generously opening his own purse. Frankly, who among musicians can be compared with him in this respect?

Anyone familiar through personal experience with the obstacles set in the path of yet unrecognized composers by their colleagues, by critics, by publishers, in a word by all those who under present conditions are only too much the indispensable intermediaries between a musician and the public, can estimate the value and the rarity of a man like Franz Liszt, all zeal in promoting the advancement of others. For it is never the multitude,-note this well;--that fails to recognize the work of genius; it may err, but it is prompt to correct the error. Those who 
through envy, prejudice or self-interest brazenly oppose the diffusion of new, truly original productions, are precisely the above-named gentlemen! Are funds needed for a monument to Beethoven?-Well and good, it is Liszt who gives money and personal effort for the project; under his musical and orchestral direction Weimar becomes the irradiating centre for all the most modern ideas and for the introduction of any new work stamped with profound personality. Berlioz while still unknown finds a friend and ardent interpreter in the Hungarian master; and many others as well who responded but inadequately to his effective sympathy. What he was to Wagner, theoretically Christian but practically more egoistically Nietzschian than Nietzsche in the flesh, I shall not here record.

Another characteristic that indelibly marks the figure of Liset and distinguishes his rare quality, - the more if one reflects that even to-day there are some who regard general culture as almost a demerit in a musician,-is his capacity for being passionately moved by everything beautiful, by Nature, by Art, by Philosophy and Religion.

It required his death, says Chantavoine in a beautiful synthetic page, to free his personality from false judgments, and the blossoming of an art that sprang from Liszt's achievements to reveal them to posterity, to show behind the incomparable but perishable virtuoso one of the most powerful creators, the boldest initiators of his century, perhaps the most generous and disinterested servant, and unquestionably the most lucid and penetrating and the broadest intelligence that the art of music has ever encountered. A mind avid of all ideas, a soul open to all aspirations, a heart sensitive to the rhythm of every enthusiasm, in the century that produced the greatest number of new ideas and tried the most new ways, set down in the midst of this compler century, shared and claimed by two countries, France and Germany, Franz Liszt was like a prism, he absorbed all their light and then diffused all the rays. Love, Nature, Poetry, Painting, Religion, all these splendors he moulded in an immense achievement, unequal, by turns very full and somewhat empty, but beautiful with life and grandeur and the origin of a new school.

And this immense work unfolds itself in symphonic poems, in pianistic forms, in religious harmonies, in letters and other writings. Liszt was undoubtedly committed to Romanticism and favored free flights of independent form; he created the pianistic and orchestral poem, evolving it from Chopin and Beethoven; he was a wonderful winged poet and dreamed as had none other of inspiring the divine art of sounds with poetic and religious feeling. Even the Gregorian melodies and tonality were now and then 
employed by him, not only in works of vast choral and orchestral proportions, but also in smaller pianistic compositions. The sonata for his chosen instrument is the most beautiful ever published since those of Beethoven and preludes the cyclic form dear to the Prench school. He reveals splendid rhythmic freedom, new, vivid, enchanting activities of color and sonority, and at the same time a melodic and harmonic purity, a truth of line absolutely Hellenic. His vast reading and culture are a preparation for translating into sounds the intimate spiritual force of the master, who found in them opportune suggestions which he selected with fine intuition and aristocratic taste.

Thus for instance the study of our divine poet inspires the symphony on "The Divine Comedy." . . . German literature stimulates the creation of one of his most perfect and profound works of grand design, "Eine Faust-Symphonie in drei Charakterbilden (nach Goethe)." ... In addition to the bias received from "obermanism," a sort of melancholy literature much in vogue after the overwhelming success obtained by the celebrated romance of Pivert de Sénancour, the work of Franz Liszt particularly revealed the influence of the French poets, as the universal Victor Hugo and the evanescent Alphonse de Lamartine. . . . Hebraic and Evangelical poetry also fascinated him irresistibly when, on the eve of fixing his residence in Rome and adopting the ecclesiastical vocation, he began writing music for psalms and masses, and the two oratorios "Die Legende der heiligen Elisabeth," and "Christus."

And now let us consider more in detail his stupendous, lururiant pianistic work which, beside the very important sonata already mentioned, the two concertos and the infinite number of transcriptions and paraphrases, notably includes the Hungarian rhapsodies and the various compositions of more particularly poetical and religious inspiration. For the modern pianist who, with eager, incessant, insatiable effort seeks to draw from the instrument, - apparently lifeless but in reality adapted to infinite transformations and developments,- ever more enchanting melody, color, shadings and diaphanous plasticity of touch, silvery, almost imperceptible, gradations of intensity of timbre and new combinations in the use of the three pedals,not merely to satisfy the offensive vanity of a virtuoso but to produce with the most beautiful of the solo instruments made well-nigh immaterial, the essential poetry of sounds, - the work of Franz Lisst is unquestionably the richest original source hitherto known. It is also an inexhaustible stream from which 
composers of the most recent tendencies draw inspiration. And what variety, what lordly abundance, what refinements, what invention of chords, of parts harmonically independent, of melodies eloquent as never any before them to communicate intense emotions; what inherent talent, what wealth of technique!"1

Indissolubly linked with Franz Liszt by ties of blood and gratitude is Richard Wagner. As men and artists they are notably dissimilar; the latter more Teutonic in ways both good and evil, the former more human and therefore more sympathetic. Liszt, great himself and modest, recognized the greatness of Wagner, set aside his own claims and in the line where for a time they had a common lot, that is the lack of appreciation and diffusion of their work as composers, the pianist, the distinguished conductor, with unselfish generosity devotes himself to advancing the fame of his friend. Wherever and whenever possible he performs his music, and with persevering effort and exquisite tact endeavours to make known the forms and ideas of the Wagnerian reform opera; and to the very frequent and insistent demands for money made by his extremely cavalier friend he never fails to respond, even at a personal sacrifice. Nor was he recompensed in kind: Wagner, solicitous only.for his own preeminence, rarely expressed a complimentary estimate of Lisat's work that had the ring of sincerity.

The moral figure of Richard Wagner, although in a different way from Beethoven and Liszt, is nevertheless characterized by sentiments of ardent virile nobility. He is a man of the theatre; toward this end flows all his energy; music itself, from the period of his first youthful emotions, seemed to him a very powerful means to a more expressive ideation of the drama; the variety of his spiritual attitudes, and even of the instruments he employed, at times chosen without great delicacy in order to obtain the desired effect, should not be judged without taking into account the height and difficulty of the goal fixed and pursued with inflexible tenacity.

As a boy he wavered in his inclinations because of the diversity of his talents and the freedom of choice permitted him in his studies by certain favorable conditions, but when fifteen years old he determined to be a musician. Spurred by the necessities of practical life, at twenty he began his activities as ripetitore and orchestral conductor and in November, 1834, he married the charming young actress, Wilhelmina Planer. From this moment

'Here follow enthusiastic pages expository of Lisst's main works for the pianoforte-Ed. 
troubles, torments, tribulations succeed each other through long years of changing vicissitudes, encountering, however, in the character of Richard Wagner a marvellously unyielding, robust resistence and combativeness. But by the very nature of the man and his work, the manner and results of the struggle were the reverse of those between the spirit and the destiny of Beethoven. And while the work of the genius of Bonn is a necessary condition to that of the genius of Leipsic, the latter integrating, as it were, the former, - the moral personality of Beethoven may appear to many of a purer humanity and a more crystalline transparency than that of Wagner.

In truth Beethoven is a hero, a most holy martyr and the Kantian imperative category made flesh: Wagner, on the contrary, is a dominator, who must triumph at any. cost, who employs action, speech and writing to impress his message on the world, to whom it is not repugnant to use means at variance with the dictates of a scrupulous conscience, or slightly histrionic, to accomplish his end; in short, Wagner is the presentiment of the modern man who "arrives,"-with the noblest and highest ideals, however, that he never betrayed. Also dissimilar were the fortunes of the two men; one lived and died in poverty, with the sole consolation of knowing at the end that his request for aid had been favorably received by the English; the other through the munificence of Ludwig of Bavaria attained the apotheosis of Bayreuth, always having found someone to supply, more or less sumptuously, the effeminate luxury that he craved, surrounded by an unenviable spectacle of neurasthenic adorers, so-called "Wagnerians,"--trumpeting to the four winds that music was born and died with the advent of their unique divinity. It is true that this plague is explained and justified, not only by the extraordinary quality and magnificence of Wagner's creations, but as a reaction from the never sufficiently aired moral narrowness and microcephalia of musical critics and professors; now, Heaven be praised! it has finally almost disappeared through the aid of time and a more serene historical and esthetic valuation. ...

What then is this work which so unexpectedly agitated to its profoundest depths the musical world of Europe? Let us first consider in a brief summary the concept of musical drama, to view later its perfected realization in opera, especially as regards the various elements of musical art in relation to the expression of the tragic idea, and then draw certain comparisons and conclusions most important to the purpose of our theme. 
Friedrich Nietzsche, in one of the most beautiful and profound of his books, that relating to the origin of tragedy, or Hellenism and pessimism, sets forth most genially the informing ideas of this admirable fruit of Greek art, and compares them with the rebirth of pessimism in the philosophy of Schopenhauer, running parallel with that of the tragic sentiment in the symphonic dramas of Wagner. Greek serenity, affirms Nietzsche, as it is understood from more or less scholastic tradition, does not correspond to the historical and philosophical reality of the mind. In the most brilliant period of Greek life this serenity is not the result of negation. or indifferent contemplation of the sorrow of the world, but rather a recognition of its perennial existence and its consequent virile subjection. In its purest form this serenity is symbolized in the myth of Apollo, the god of light, and Olympus, the seat of the gods. The Apollonian cultus is the manifestation of the radiant vision of the world, by force of which it is viewed objectively as though reflected in a mirror of shining brightness, and the image of its eternal immutable travail is softened by the very beauty of the vision, by the dream, by Art. In other words, Hellenic serenity is not the spiritual condition of those who profess a vulgar short-sighted optimism, for it necessarily presupposes a pessimistic "Weltanschauung" subdued and overcome by the divine restorer, by the pure ambrosia of the plastic art and the Epopoeia. In the heavens of Apollonian culture the Homeric poems shine as stars of the first magnitude. Quite the reverse is the tragic Dionysiac spirit; whereas, under the influence of Apollo the individual dominates sensuality and suffering by the well-regulated serenity of the esthetic vision, under that of Dionysius the will of nature creates, destroys, exterminates individuals and, an unwearied generator, is never satiated with ineffable emotions and torments. From the divinity of Dionysius spring music, lyric art, tragedy and the dramatic dithyramb. But, since life as it is, with its events pleasant and painful, its passions productive of sublime virtue and low vice, is not art unless Apollo with his magic stroke endows it with the confident calm of the contemplative spirit, it follows that the winged lyrics of Archilochus and Pindarus, the tragic force of Aeschylus and Sophocles, the very essence of music, are inspired by a living, penetrating fusion of the spirits of Apollo and Dionysius. The more immediate origin of tragedy is in the chorus; not as traditionally understood in the significance of the ideal spectator or as incarnating the ethical law of the Hellenic people, but regarded, according to Schiller and Nietzsche, as affirmation of the dominion 
of the ideal, and of poetic freedom, as symbol of a religious reality recognized under the sanction of the myth and of worship. The chorus alone at first; then the chorus in the orchestra, and finally Dionysius on the stage. But the divine harmony of instinctive wisdom, the starry light of the spirits of Apollo and Dionysius, the genius of music which is at the source of tragedy,-and through which-Wagner said well-the effects of so-called civilization are demolished just as the pale light of a lamp is quenched by the glorious day -are obscured as it were by the Socratic principle. Socrates is the emblem of man's ratiocinating force; Euripides, the tragedian, sucks its slow corroding poison; the dialectic optimist dispels the chorus and music from tragedy, thus destroying its very essence; the frozen calm of the theorist succeeds the fervid serenity that imbibes divinity from Apollonian and Dionysian wisdom; scientific criticism consumes the sacred balm of legend and myth, of national and religious faith by which every great art-especially the Hellenic-was nourished.

All this seemed at first to Nietzsche to find a parallel in Germany with the metaphysics of Kant and Schopenhauer, with the music of Beethoven and Wagner-considered as the art of transcendental consolation antagonistic to the optimism of modern Alexandrian culture. In the esthetic, tragic, Socratic or Alexandrian conception of the world, art, music and science are parallel, dissimilar images of the universe. Modern man, already affected by the mania for analytic inquiry and committed to an optimistic faith in scientific research and the results of progress, is serene in the Socratic sense, but through Wagner's music the myth is being reborn and with it instinctive wisdom; the theoretic Alerandrian spirit is put to flight by those of Apollo and Dionysius; the pessimistic "Weltanschauung" triumphs over discipline of action and the Hegelian satisfaction with self, with the facts of history. Nietzsche, howeyer, is in error when he affirms that the representative style of our composers of the 17th century arose from the action of an idyllic tendency extraneous to the essence of art and tragedy; he is right when he opposes opera as commonly understood to the symphonic drama of Richard Wagner, and considers that the progressive reawakening of the tragic Dionysian spirit in our age has kept step with the music of Bach, of Beethoven and Wagner, with the philosophy of Kant and Schopenhauer,true renascence of the Dionysian principle hostile to the Secratic Alezandrian. In fact, the whole development of Germanic thought in the last century is affected by the tendency to 
confound German culture with the Greek: the purifying and liberating force of tragedy aims to introduce, by the universal action of music, subjecting the hearer to the Dionysian influence, the myth as a sublime symbol; the revival of the bellicose instinct,I am still speaking of the 19th Century, - the rebirth of the tragic myth, and the Germanic musical drama opposed in conception to the old opera of Socratic tendency are signs of the ardent, passionate aspiration toward radiant Hellas;-"the Dionysian instinct, with its primordial joy even in the presence of sorrow, is the common womb from whence issues music and the tragic myth."

There is no contradiction between the two attitudes of Nietzsche, at first favorable then hostile toward the work of Wagner, but a development of thought and a clearer consciousness of identical personal idealities. To understand this it suffices to penetrate the mind of the former as revealed in his numerous volumes. Nietzsche and Wagner were both, at a certain point of their intellectual life, fascinated by the ideas of Schopenhauer, and each saw in him a sign auguring well for the new Germanic life and the resurrection of tragic sentiment. The theory of the Dantzic philosopher united them particularly at the point where the Platonic idea is declared the object of art,-an impersonal contemplation of the universe by which the individual rises to a state of pure subjectivity whose whole content is pure objectivity, while music with its marvellous intuition is considered outside of the hierarchy of the other arts, as an expression not of Ideas, but of the Will itself parallel to them. This is a translation into the language of Schopenhauer of the Apollonian and Dionysian principles from which arise on one hand the epic and plastic arts, on the other tragedy and music. However, in Nietzsche pessimism was always more or less clearly subdued by the will to power, by a vision of the world becoming paganized and antichristian, by a bold, ardent, superb glorification of conflict and of life beyond good and evil, by a nostalgic aspiration toward the southern sun and the ethereal lightness of Greek and Roman art. Schopenhauer and Wagner, on the contrary, became drowsy and ponderous under the narcotics of the Buddhistic annihilation of the will, of the Christian negation transplanted in Teutonic soil, of undigested and unspeakably dull and soporific Northern legends and mythology. Hence there is nothing to awaken wonder or sinister interpretation in the fact that Nietsche's mind, supremely artistic, after the first unconscious Wagnerian intorication, penetrated more deeply his own inner spiritual 
visions and was forced to diverge from the common standpoint."

Wagner's life-work is assuredly among the most powerful recorded by history, for the vastness of its conception, for the profound and inexpressibly suggestive personality of the musical content as well as the scenic vision, and for a most original use of means of expression. The system of leading motives is, like all methods presstablished by the reasoning faculty when it usurps the office in art belonging properly to intuition, very open to criticism. It is not new, although never before the time of Wagner was it developed 80 completely and at times with such magnificent effect; Beethoven himself, who in Fidelio took a decisive step forward in the history of the modern lyric drama, similar to that marked in the history of the symphony by the composition of the Fifth, had resolved to employ the "leitmotiv" in another opera, planned but not completed. Nevertheless, when one listens to the last scene in "Die Walktire" or in "Gotterdammerung," for instance, what words can serve to express the emotion that stirs the inmost fibres of the soul? And how foolish then appears any discussion of method! The originelity and penetrating expression of the melodic discourse, the harmonic woof extraordinarily chromatic and dissonant even to those familiar with Monteverdian tonalities, the always full and richly poetic orchestration, of homogeneous impasto and varied in coloring, the eagle-like amplitude of the lyric flight, the Michelangelesque strength of design and dramatic content, all solemnly consecrate to posterity the work of Richard Wagner as an indestructible monument of towering grandeur, even when viewed from the especially musical standpoint. It is true that he often sacrificed the voice, the chorus and the dance to instrumental richness; his dramatic inspiration frequently drew its vitality more from the orchestra than from the stage, - but precisely in the reaction from such errors lies a fruitful germ for the future!

Of the school more particularly French, let us now briefly mention Berlioz and Franck. Not sufficiently personal the versatile Saint-Sacens nor Bizet, the very talented writer of operas; neither of them can claim a place beside the first two names on the great historical roll. The development of this school cannot be explained without taking into account the lively penetration

'The enthor here illurtrates bis point of view by a quotation from Nietreche' Also oprach Zarathustra' and by a quotation of those wonderfally penetrating pagee D d'Anuunsio"s "Il fuoco" in which dwe homage is paid to the geniua and greatness of Warner, but in which aloo the gull betwoen bis and the Latin opirit is lajd bare. $-E d$. 
of foreign tendencies, from Beethoven to Liszt, from Wagner to Strauss; a decisive influence on all contemporary art, which, like the preceding, is the story of various and reciprocal infiltrationsaccording to the period, - of Flemish, Italian, German and other elements. Whether such penetration, prejudicial to the permanency of nationality, be beneficial, it will not be difficult to decide; it is essential and inherent in human nature itself,which is the same through all diversity of places, climates, traditions and ideas, - if only its action does not alter their peculiar qualities or the characteristics of individuals. The dream of Wagner, which was precisely the creation of a profoundly national art in opposition to the invading Italian and French opera, is most instructive in this regard. But do not, I beg of you, confound, as is sometimes done with us, to impress the timid, the uncertain and the uncultured, Italian music with art and,-absurd as it sounds, - with vulgarity, German music with science and frigidity. Art, I repeat, is above all a manifestation of personality and humanity, and I have expressed elsewhere my disapproval of foolish prophetic judgments. Has then this modern penetration been verified in Italy? Giuseppe Verdi's marvellous "Falstaff," Arrigo Boito's noble "Mefistofele," the chamber music and symphonic works of Antonio Bazzini, Giovanni Sgambati and Giuseppe Martucci are the only productions in modern Italian history worthy of serious, profound consideration. Of the silly performances botched together for the sole end of lucre by the so-called young and very young school, I say nothing. A few dignified attempts, a few more or less recent names are noted in the world of pure and dramatic music, none as yet truly significant for original power or synthetic completeness.

Berlioz and Franck were very unlike in character, life and thought. The former eager for glory and riches, for action, for personal and artistic strife, not always kind or grateful for benefits received, but generous and averse to compromises with his own austere musical conscience. He was a litt6rateur and journalist; he travelled in various parts of Europe, sometimes insufficiently appreciated, often receiving much applause; he experienced many times the tremors and torments of love and wrote under its impulse; certain works he admired, but more often he despised, failed to comprehend, or was ignorant of the true value of illustrious contemporary colleagues, for instance of Liszt and Wagner, who both, especially the former, - need it be said?-esteemed and encouraged him. Less universal than Wagner and more concerned with his own interests and his own art, whereas the former in 
Dresden is inflamed by the revolutionary movement that ends with the catastrophe of May, 1849, Berlioz is overwhelmed by the February revolution and understands nothing of the profound changes that are ripening. Everyone knows in what fashion Weimar, for a certain period, through the efforts of that beneficent genius, Liset, was the cradle where the most daring works of art,-those saturated with new ideas,-were nourished with maternal loving care. Berlioz profited largely by this, and yet without a shadow of reason or justice he ended by slandering his friend, the Hungarian composer. Wagner also, usually averse to showing interest in anyone but himself, held in due esteem the work of the French master, who, however, despised the so-called "music of the future" and gave credence to the evil reports concerning it then current. Although restless and sick with nerves, Berlioz led a life not deprived of satisfaction; he was familiar with poverty, having left the home roof in early youth to follow his chosen path, but he received excellent earnings, valuable gifts and family legacies. As an artist he was essentially romantic in the widest acceptation of the word: "romantic"says J. G. Prod'homme - "in the disregard of rules, in his lack of proportion, in his abuse of hors d'oeuvres, and especially in his pursuit at whatever cost of the picturesque, the horrible, the colossal, of violent contrasts; romantic also in the pose with which he complacently stepped before the public in $L ' E$ pisode de la $V$ ie d'un Artiste, in Harold as the heroes of Byron and Goethe, the chosen types of his first episode." In the symphonic and religious domain, as in the theatrical, Berlioz has left traces of signal beauty and personality: it is a pity that his most important music is so little known in Italy. With the "Symphonie fantastique," for example, he established the creation of program music, and in "Benvenuto Cellini" he perfected, as wrote Franz Liszt about the middle of the last century, the most considerable and original achievement of lyric dramatic art that,-aside from Wagner's incomparable works, - had appeared in the last twenty years. His treatise on instrumentation and orchestration is the first and most important for completeness, poetry and color-vision; perhaps Gevaert's alone,-which is much later,-excels it in discerning acuteness of method. At the end of this magnificent book, in the chapter entitled "L'orchestre," having depicted an ideal complex of voices and instruments, he concludes with these impressive words:

In the thousands of combinations possible with the monumental orchestra that we have just described there would dwell an harmonic richness, a variety of timbres, a succession of contrasts comparable to 
nothing hitherto produced in Art, and more than all, an incalculable melodic potency, expressive and rhythmic, a penetrating force beyond any ever known, a prodigious sensitiveness to the nuances of ensemble and detail. Its repose would be as majestic as the slumber of the ocean; its agitations would suggest tropical hurricanes, its explosions the crash of volcanoes; in it would be heard once more the plaints, the murmurs, the mysterious noises of the virgin forest, the outcries, the prayers, the songs of triumph, or of mourning, of a people of expansive soul, ardent heart and fiery passions; the solemnity of its silence would a waken fear, the most rebellious would tremble as its crescendo increased, roaring like a huge sublime conflagration.

Such is the style of the man, such the dream of the artist! César Auguste Franck was a most pure and candid mind, without resentment, without rancor; hate he did not know, hence he was unable to translate it into notes; he fervently loved art, humanity, religion and the contemplative life. His days passed in even and quiet rhythm; the first morning hours he dedicated to his own work, the rest to imparting instruction that was efficacious and decisive in its result on recent French musical art, and to the performance of his duties as church organist and professor at the Conservatory. Only during the summer vacation had he leisure to devote to the composition of his ad- . mirable works, and to the perusal of the most elevated literature on human thought. It was at Quincy that occurred the episode mentioned at the beginning of this study. One morning he was walking in the garden of his little summer home; with brow contracted he was meditating intently on a weighty volume and at the same time smiling. "What are you reading so funny?" asked one of his sons. "A work by Kant, The Critique of Pure. Reason-it is very amusing," replied the father, a fervid, profound sincere Catholic. And in truth, religion was coëssential to his spirit which, $\longrightarrow$ of angelic goodness, free from all but the most noble aspirations, - seemed to be not of this world. The neglect, the ingratitude and unkind treatment on the part of his extremely narrow-minded colleagues he never perceived or would not admit. A few enthusiastic pupils, who were to carry forward the torch of the French musical renascence, understood and loved him; Liszt, as usual, delighted in him from the appearance of his first compositions. Ambroise Thomas, the arrogant director of the Conservatory, the mediocre author of "Mignon" and "Hamlet," feigned, as did some others, a convenient indisposition to avoid attending the obsequies of the truly great artist for fear of exposing himself to the risk of being thought favorable to the abhorred musical vanguard. 
Adieu, Master, - agid Emmanuel Chabrier at the tomb,-and we thank you, for you have done well. We salute in you one of the greatest artists of the century; we salute also the incomparable teacher whose instruction has caused to flower a whole generation of robust musicians, capable of faith and reflection, armed at every point for severe, sometimes long contested combat; we salute in you also the just and upright man, truly humane and unselfish, who never gave aught but safe counsel and helpful words. Adieu!

It may be that Franck was not thoroughly familiar with Gregorian and Palestrinian art, but he infused a breath of intimate mysticism into a few religious works quite particularly Latin; he treated the symphony, the quartet, the pianistic and organ forms absolutely with the understanding of a renewer, absorbing, however, from the art of Beethoven its vigorous and vital quality; he was so much in harmony with Bach that, as improviser and author of works for the two sovereign keyboard instruments, he seemed at times to be his modern reincarnation. Take as an example of Franck's last and most significant period, the prelude, choral and fugue, or the aria, prelude and finale for piano, and note the depth of sentiment, the inexhaustible riches of harmonic succession, of thematic work, of polyphonic play, the freedom and novelty of rhythmic forms, contained, however, within architecture of classic purity. And who does not recall the string quartet, the symphony, the quintet with pianoforte, the sonata for piano and violin, not to mention the sublime pages scattered through his oratorios, his dramatic and other works. Cessar Auguste Franck, in his masterpiece dedicated to Eugene Ysaye, definitively consecrated the cyclic form destined to so high a place in the more modern symphonic art. He likewise inherited from Beethoven the variation, and amplified it atill more richly.

The times are weighty with extraordinary events. The human world is being turned upside down and renewed from roots to branohes. In the divine art of sounds great destinies are also maturing. Ludwig van Beethoven is like an ancient trunk of immeasurable height, solidly, deeply fixed in Mother Earth; from him propagate themselves other roots, new, green, luxuriant branches are spreading, flowers, fruits and young twigs are growing. Without his art would not have existed program music, or the colossal Babylonian, sonorous structures of Berlioz, the pianistic and symphonic poems of Chopin and Liszt, the musical drama of Richard Wagner, or the Apollonian mystic forms of Franck. Without his adamantine labor, neither the orchestra, nor the meloepia and ritmoepia, nor the harmonic and 
polyphonic elaboration, could have followed the perfected path of the present musical tendencies.

Let us incline our heads as at a sacred rite,-to-day more than ever, when Dionysius is again arising and with him the hope of a life more spiritually complete,-before Ludwig van Beethoven first of all, then before the other creators of modern musical idealities, who preserved and passed onward the clear flame of the purifying art in endless ascension. Let us study and perform, as well as the more ancient, the works of these great artists. Let us rejoice in their new forms, vocal, instrumental and harmonic; and, more than all, let us penetrate their individuality and profound humanity, begotten of the travail of sorrow and love.

In these latter days too many weak, esthetic draughts are offered us. Claude Debussy and Maurice Ravel, Max Reger and Arnold Schønberg, Alexander Scriabine and Igor Strawinsky merit our loving attention because they aspire to widen the horizons of technical expression in musical art: in rhythmic freedom as well as in orchestral coloring, in vocal recitation, in mimetic and suggestive symbolism, and by overthrowing the harmonic and formal prejudices that are still very prevalent. As regards the latter I have sufficiently expressed my opinion. And now may our professors of harmony pardon me: their canons are dead: all the twelve sounds of the chromatic scale are-I think-quite prepared to form every possible combination of from two to twelve notes! Great therefore is the enrichment of expressive instruments due to these contemporary minds, who in diverse ways are following in the footsteps of the five greater masters. Nevertheless, in their music-sometimes more, sometimes lesstheoretical illustration and mechanical elaboration dominate the lyric impulse and creative force; the rational faculty conquers the intuitive; intellectuality dries up inspiration. They are means, not ends, in History. ... 